T. JiA, M. ZHANG, S. P. MCCOLLOM, A. BELLOMO, S. MONTEL, J. MAO, S. D. DREHER,

C. J. WELCH, E. L. REGALADO, R. T. WILliAMSON, B. C. MANOR, N. C. TOMSON*,

P. J. WALSH* (UNIVERSITY OF PENNSYLVANIA, PHILADELPHIA, MERCK \& COMPANY, INCORPORATED, KENILWORTH, USA AND NANJING TECH UNIVERSITY, P. R. OF CHINA) Palladium-Catalyzed Enantioselective Arylation of Aryl Sulfenate Anions: A Combined Experimental and Computational Study

J. Am. Chem. Soc. 2017, 139, 8337-8345.

\title{
Enantioselective Palladium-Catalyzed Synthesis of Diarylsulfoxides
}

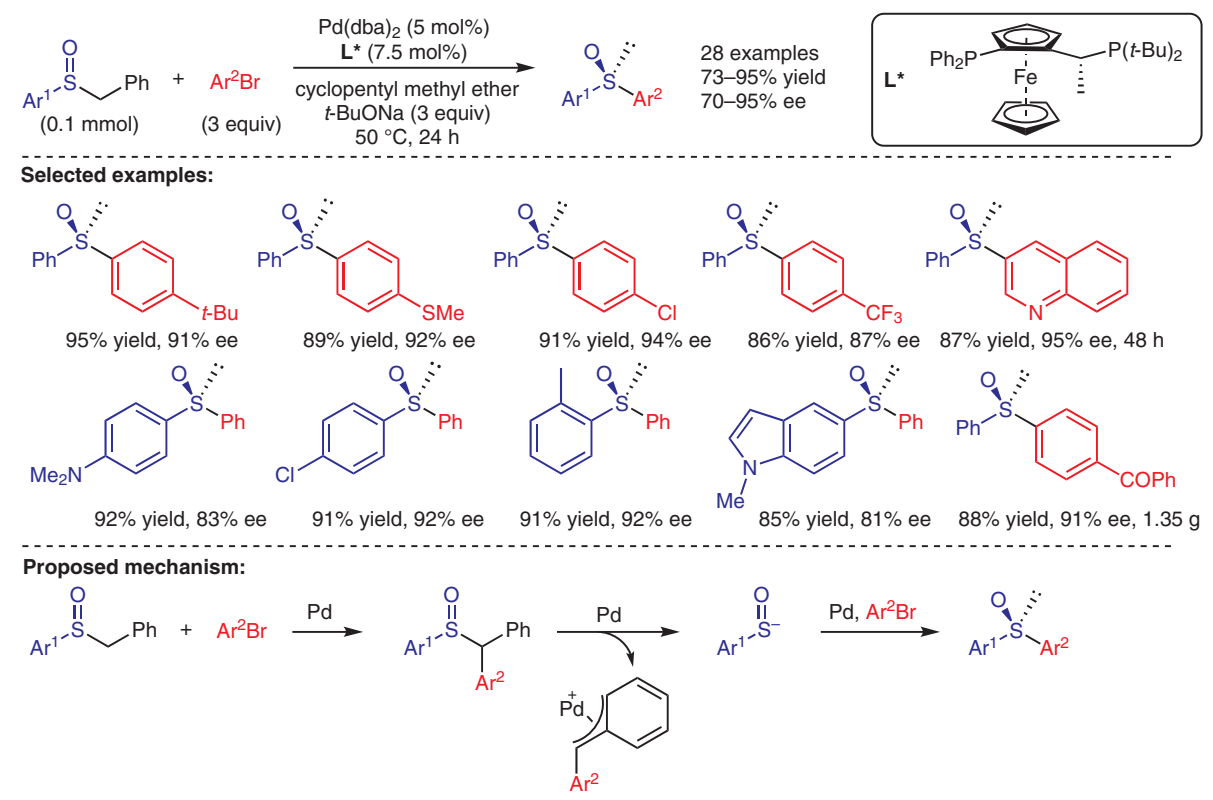

Significance: Enantioenriched sulfoxides are present in many bioactive molecules and they serve as valuable reactive handles for further transformations. Their synthesis generally relies on enantioselective oxidation of the corresponding sulfide, which can suffer from substrate limitations and over oxidation. Tomson, Walsh and coworkers report the synthesis of chiral diarylsulfoxides through the generation of sulfenate anions in situ and their subsequent enantioselective coupling to aryl bromides. The authors obtained high enantioselectivities, which would be challenging with oxidation methods because of the similarity of the two aryl groups. This is a dynamic kinetic asymmetric transformation because the sulfoxide stereocenter is initially removed and the chiral catalyst selectively generates one of the diarylsulfoxide enantiomers.

SYNFACTS Contributors: Mark Lautens, Andrew Whyte Synfacts 2017, 13(09), 0935 Published online: 18.08.2017 DOI: 10.1055/s-0036-1591173; Reg-No.: L09017SF

\section{Category}

Metal-Catalyzed Asymmetric Synthesis and Stereoselective Reactions

\section{Key words}

palladium catalysis

chiral sulfoxides

dynamic kinetic asymmetric transformation

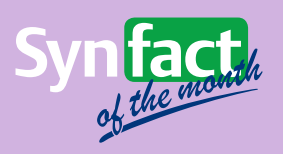

Comment: The reaction utilized a chiral JosiPhos ligand and required a three-fold excess of aryl bromide because one equivalent was consumed when it generated the sulfenate anion. Succesful substrates are phenyls with both electron-rich and electron-poor groups as well as heteroaromatics, which would not be compatible with conventional oxidation methods. Notably, both enantiomers of the product could be generated with a single enantiomer of the ligand by switching the aryl ring of the sulfoxide substrate and the aryl bromide. A large-scale experiment was conducted using a ketone-containing aryl bromide, giving good yields and enantioselectivities. The reaction proceeds via a sulfenate anion generated by an initial $\alpha$-arylation of the sulfoxide followed by cleavage of the $\mathrm{C}-\mathrm{S}$ bond. The sulfenate anion is trapped by an oxidative addition complex of another aryl bromide followed by reductive elimination. 